rev.relac.int.estrateg.segur.13(1):119-145,2018

\title{
Reino Unido y Argentina: geopolítica de la limitación tecnológica y controles de exportación estratégicos*
}

\author{
Daniel Blinder $^{* *}$
}

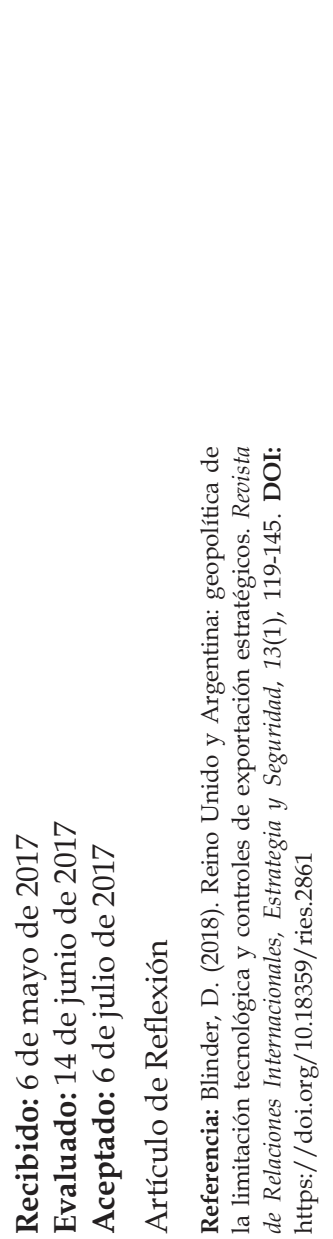

\section{Resumen}

El presente artículo se propone estudiar la geopolítica de la limitación tecnológica por parte del Reino Unido a la República Argentina utilizando controles de exportación de tecnología militar o de uso dual. Para ello usa instituciones de defensa y de comercio del Parlamento británico, pero también instituciones internacionales. Además, se analiza la documentación publicada por dicho Gobierno, referida al país suramericano en materia de control de exportaciones, cuya política pública está supeditada a decisiones de índole estratégico, tanto a nivel local como global, representadas en la lógica espacio/poder por las

\footnotetext{
El presente artículo es el resultado de una investigación posdoctoral financiada por el Consejo Nacional de Investigaciones Científicas y Técnicas (Conicet), de la República Argentina. Los resultados preliminares de este trabajo han sido presentados en 2017 al IV Congreso Latinoamericano y Caribeño de Ciencias Sociales en Salamanca, España.

* Licenciado en Ciencia Política y Doctor en Ciencias Sociales, Universidad de Buenos Aires (UBA); magíster en Defensa Nacional, Escuela de Defensa Nacional. Investigador del Centro de Estudios de Historia de la Ciencia y la Técnica José Babini, Universidad Nacional de San Martín (UNSAM), y Profesor de Geopolítica de la UBA y de Tecnología y Relaciones Internacionales, UNSAM. Correo electrónico: dblinder@unsam.edu.ar.
} 
Malvinas. Se verá cómo las instituciones gubernamentales se ocupan de atacar los resortes institucionales por los cuales la Argentina pudiera acceder a tecnologías sensibles; es decir, limitando la adquisición de capacidades que redundarán en poder militar y que amenacen los intereses de las islas. La evidencia de las fuentes consultadas demuestra que dicha política ha sido explícita y abierta, y ha sido exitosa, lo que ha limitado la adquisición de tecnología británica.

Palabras clave: geopolítica; tecnología; Argentina; Reino Unido; Malvinas.

\title{
The United Kingdom and Argentina: geopolitics of technological constraint and strategic-export controls
}

\begin{abstract}
The present article aims to study the geopolitics of technological constraining by the United Kindom to the Argentine Republic using export controls of military technology or dual use. It uses British defense and trade institutions, but also international organizations. Also, it analyzes the documentation published by said Government, referring to the South American country in the matter of export control, whose public policy is subject to strategic decisions, both locally and globally, represented in space / power logic by the Malvinas. It will be seen how governmental institutions are engaged in attacking the institutional springs by which Argentina could access sensitive technologies; that is, by limiting the acquisition of capabilities that will result in military power and threaten the interests of the islands. Evidence from the sources consulted shows that this policy has been explicit and open, and has been successful, which has limited the acquisition of British technology.
\end{abstract}

Keywords: geopolitics; technology; Argentina; United Kingdom; Malvinas.

\section{Reino Unido e Argentina: geopolítica da limitação tecnológica e de controles estratégicos de exportação}

\section{Resumo}

Este artigo tem como objetivo estudar a geopolítica da limitação tecnológica do Reino Unido para a Argentina, usando controles de exportação sobre a tecnologia militar ou de utilização dual, mediantes instituições Defesa e Comércio do Parlamento britânico, mas também aquelas internacionais. Documentação publicada por esse governo referiu-se ao país sul-americano sobre o controlo 
de exportação, cuja política pública depende de decisões de natureza estratégica, tanto local como global, representada no espaço lógica/poder sobre as Malvinas. Será visto como instituições governamentais interessadas em atacar as fontes institucionais pelo qual a Argentina poderia acessar tecnologias sensíveis, e limitar a aquisição de capacidades que resultarão em poder militar, e que ameaçam os interesses das ilhas Malvinas. A evidência empírica das fontes mostras que esta política tem sido explícita e aberta, que limita á Argentina a aquisição de tecnologia britânica.

Palavras-chave: geopolítica; tecnologia; Argentina; Reino Unido; Malvinas.

\section{Introducción}

El presente trabajo tiene por objetivo analizar la geopolítica de la limitación tecnológica de los países centrales a partir de los controles de exportación de tecnología militar o de uso dual que se ejerce a partir de instituciones específicas del Estado para su control. Para tal fin, se hace un estudio sobre la documentación publicada por el Gobierno del Reino Unido de Gran Bretaña, como análisis de caso en la limitación de transferencia tecnológica a la Argentina. El Reino Unido mantiene intereses en determinados territorios del globo, pero no mundiales como Estados Unidos. Sin embargo, tiene una alianza estratégica con dicho país y coopera con él en sus relaciones bilaterales e internacionales. Los británicos mantienen intereses territoriales coloniales como en el caso de las Malvinas, denominadas por ellos Falklands. Se analiza, además, cuál ha sido la política del Reino Unido, en relación con las limitaciones impuestas a la Argentina tras la Guerra de Malvinas de 1982, hasta 2016.
Mariana Mazzucato (2013) describió aquellas condiciones por las cuales un Estado alcanza el desarrollo tecnológico, y es justamente desde la activa intervención estatal que se consiguió tecnología de punta, antes de que dichos productos tecnológicos ingresaran en el sistema del mercado. En efecto, la autora señaló que las fallas de mercado no existen y que es un error pensar que pueden corregirse mediante la intervención del Estado, y generar así incentivos y condiciones para que se corrijan y puedan existir inversiones productivas e innovación. Por el contrario, el Estado genera las condiciones para que exista innovación y desarrollo invirtiendo desde el fisco activamente parte del presupuesto para desarrollar sectores estratégicos. El Estado genera condiciones para el desarrollo, los capitales privados son aversos al riesgo. La investigación básica la financia el sector público, y cuando llega el momento de comercializar, interviene la inversión privada.

En el siglo XX en Estados Unidos, algunos desarrollos industriales de tecnología 
de punta han sido los impulsores del desarrollo y del poder económico, militar e internacional, y conjuntamente estos desarrollos han estado a la vanguardia de la innovación de la economía mundial. Las tecnologías maduras han sido un grupo de tecnologías comerciales que inicialmente estuvieron fuertemente vinculadas a la investigación y desarrollo militar, y las adquisiciones para la defensa (Ruttan, 2006, p. 5). Vernon Ruttan (2006) estudia tecnologías de propósito general -aquellas que de su desarrollo se integran o desarrollan nuevas tecnologías- en el contexto industrial estadounidense: las partes intercambiables y la producción en masa, los aviones comerciales y militares, la energía nuclear y eléctrica, computadoras y semiconductores, la internet y la industria espacial.

Así, estas tecnologías están relacionadas directamente con el territorio y con la imaginación geopolítica sobre él. La imaginación geopolítica de los actores internacionales puede ser definida como una visión del sistema internacional, su funcionamiento, y de los otros países en particular. Algunas características se le pueden atribuir a ciertos Estados que son distintas de las de otros. En consecuencia, existe un discurso geopolítico acerca de cómo son leídos los acontecimientos políticos y económicos, y cómo es representado el poder en el espacio, cómo es y cómo debería ser (Agnew, 1995, 2005). La geopolítica ofrece imágenes del paisaje global utilizando descripciones geográficas. Términos como
"Cortina de Hierro, Tercer Mundo, o Estado Canalla son términos inherentemente geográficos porque los lugares son identificados a partir de estos términos, e informan a los decisores de política internacional" (Dodds, 2007 , p. 4). Cada metáfora nos dice mucho de un lugar, como qué característica tiene ese lugar, dónde está y en oposición a qué. Un Estado del primer mundo o del centro configura una representación de un país con una economía desarrollada, diversificada, tecnológicamente avanzada y un Estado influyente y poderoso del sistema internacional. Un Estado tecnológicamente desarrollado tendría entonces mucho poder y un sistema productivo que lo sostenga. ¿Puede pensarse un Estado tecnológicamente avanzado, desarrollado, por fuera del sistema interestatal? De ninguna manera existen nociones metafóricas sobre el desarroIlo porque estas también existen sobre el subdesarrollo. Los países avanzados desarrollan reglas, instituciones -tanto nacionales como internacionales - que regulan el desarrollo y la tenencia tecnológica. Las más sensibles y reguladas son las bélicas.

La relación entre guerra y geopolítica ha sido estudiada por Yves Locoste, que ha determinado que la estrategia de bombardear el territorio adyacente a diques del río Rojo en Vietnam por parte de Estados Unidos tenía la lógica de inundar a la población cuando sucedieran las crecidas de las aguas (Lacoste, 2011). ¿Cuál era el propósito de los bombardeos? No era bombardear los diques (la tecnología en sí 
directamente), sino lugares estratégicos del territorio en cuyo lugar se montaba la extensa estructura subterránea del dique. Podemos afirmar que la estrategia geopolítica es la misma con la tecnología: atacar aquellos puntos de apoyo institucionales sobre los cuales se asienta el desarrollo tecnológico. Los puntos son las instituciones y la economía. Si se ataca el asiento institucional y económico no podrá existir desarrollo tecnológico. Esto es lo que ha hecho el Reino Unido tras la Guerra de Malvinas de 1982 con la Argentina. Limitar tecnológicamente a la Argentina para que no desarrolle su capacidad militar, pero tampoco capacidades tecnológicas. Por lo tanto, la Argentina quedaba como un país peligroso para la imaginación geopolítica de los políticos británicos, y asimismo como un objeto de políticas institucionales que limitaban la actividad económica en tecnologías que pueden considerarse de uso militar.

Las evidencias empíricas están basadas en los propios documentos temáticos publicados por el Gobierno británico entre 1997 y 2016. Como explica Lacoste (2011), todo razonamiento geopolítico, para ser global, debe ser llevado a cabo a partir de distintos niveles de análisis espacial a un nivel planetario y local. La estrategia del Reino Unido es global por tener una geopolítica de limitación tecnológica enganchada con los intereses globales de su economía, pero también la de sus aliados, los Estados Unidos. No obstante, la estrategia es igualmente local, y responde a los intereses de los habitantes de las islas Malvinas (kelpers) y de los británicos en la región del Atlántico Sur.

\section{El Reino Unido tras Malvinas}

Después de la derrota argentina en la Guerra de Malvinas, y quebradas las relaciones diplomáticas, los británicos ejercieron presión para mantener limitado el poder de fuego de los vencidos. Una serie de prohibiciones efectuadas por un embargo constituyeron la medida adoptada por el país europeo tras la ocupación del territorio insular en disputa por parte del aparato militar de Argentina (Martin, 1992). Una de las mayores preocupaciones del Gobierno de la Corona era mantener desarmado por el mayor tiempo posible a la Argentina, con el objeto de neutralizar sus capacidades militares presentes y futuras. El embargo internacional de los aliados del Reino Unido pronto empezó a levantarse, y algunos equipamientos militares fueron vendidos al país sudamericano, por ejemplo, ventas de armas por parte de Francia e Italia (Phythian, 2000).

A la sazón, y no obstante ello, el Reino Unido levantó parte del embargo a la Argentina para facilitar el cumplimiento de los contratos con sus socios comerciales europeos, que en sus maquinarias bélicas utilizaban componentes de industria británica. Así, cuatro turbinas Rolls-Royce y material de propulsión y electrónica de la firma BAE fueron autorizadas para destructores argentinos de origen alemán 
occidental. También, las naves portarían helicópteros Westland Linx de fabricación británica y misiles Exocet que, si bien eran fabricados en Francia, estaban manufacturados con partes británicas (Phythian, 2000). Los aviones Mirage frances y los Dagger israelíes funcionaban con un motor Rolls Royce 540 Viper. A pesar de esto, el Gobierno de Thatcher siempre hizo lobby en las sombras para garantizar el embargo y, por lo tanto, la restricción del acceso al mercado internacional de tecnología armamentística para la Argentina. El embargo perduró hasta que durante la presidencia de Carlos Menem se recompusieron las relaciones bilaterales, cosa que se concretó en 1998 (Phythian, 2000).

Es importante destacar que, si bien el Reino Unido ha perdido su lugar como potencia mundial tras la Segunda Guerra Mundial, no ha dejado de ser un país con industrias estratégicas, cadenas globales de valor, intereses corporativos multinacionales y participación clave en asuntos estratégico-militares. En efecto, cualquier sistema tecnológico industrial está basado en una matriz de uso dual, cuyo resultado es el desarrollo de productos industrializados con propósitos bélicos y comerciales. Al finalizar la Segunda Guerra Mundial, una gran masa de inmigrantes científicos de Europa se dirigió hacia Estados Unidos, momento desde el cual este Estado se convirtió en líder en producción industrial y científica. La inversión en este rubro a partir de los atentados terroristas en Nueva York y el Pentágono de 2001, habiendo dis- minuido en términos relativos durante la década de los ochenta y los noventa, creció mucho en el sector militar. El conocimiento científico creó negocios multinacionales vinculados a la industria de armamento (Blinder, 2016). En 2014, de acuerdo con el Stockholm International Peace Research Institute (Sipri), el Reino Unido estaba entre las 100 empresas más importantes de desarrollo militar, cuyos productos manufacturados no son solamente de uso para la guerra. Nueve empresas de esa nación y tres en las que este país participa en un consorcio europeo figuran en una lista en la cual predominan las empresas estadounidenses, y en la que la tercera del ranking es británica. Figuran BAE Systems, Airbus Group, RollsRoyce, Babcock International Group, MBDA, Serco, Cobham, QinetiQ, GKN, Thales UK, Meggitt, CNH Industrial. Después de Estados Unidos, con un $54,4 \%$ largamente, la participación del Reino Unido es del 10,4\%, la segunda en porcentaje (SIPRI, 2014b, 2015).

Por otro lado, el Reino Unido mantiene un embargo a la República Argentina debido a que el conflicto entre las naciones escaló desde diciembre de 2011, cuando los países del Mercosur (Argentina, Brasil, Paraguay y Uruguay) decidieron no permitir el acceso a sus puertos a barcos con bandera de las Falklands británicas (La Nación, 21 de enero de 2012). De acuerdo con una declaración ministerial del parlamento en Londres, en 2012 se realizó un cambio de política con respecto a la Argentina en cuanto a las licencias de exportación y de comercio para britá- 
nicos de bienes controlados y de tecnología militar para usuarios finales. El informe parlamentario muestra que una política previa fue el cambio mencionado más arriba (de 1998) y llevado a cabo por Menem en el cual, si bien seguía existiendo un embargo de tipo militar, se permitiría la exportación de ciertos bienes para uso militar de capacidades de combate existentes, mas no nuevas. Este cambio y endurecimiento fue debido a las acciones diplomáticas de los países del Mercosur tendientes a dañar la economía de las Malvinas, aseguró el informe, y solo afecta a las licencias de exportación para usuarios finales de la Argentina (Business, Innovation and Skills, 26 de abril de 2012).

No obstante, la Argentina es sujeto de controles de exportación británicos junto a otros países, como Afganistán, Burundi, La Región Administrativa Especial de Macao en China, Rwanda, Tanzania, Uganda ${ }^{1}$. La República Popular China tiene controles para la exportación de tecnología militar y la Federación Rusa sufre sanciones por parte de la Unión Europea (Gov.uk, 3 de agosto de 2012). Estas restricciones de exportación tecnológica refieren a material sensible, no solo en relación con armamentos de destrucción masiva, sino también a software y tecnologías que podrían terminar componiendo una tecnología de alto desarrollo y uso dual (Gov.uk,
11 de septiembre de 2012). La lista de materiales de la Unión Europea de control de exportaciones, a las que el parlamento británico adhiere, son materiales nucleares y su equipamiento, químicos, microorganismos y toxinas, materiales de procesamiento, electrónicos, computadoras, telecomunicaciones y seguridad de la información, sensores y lásers, navegación y aviónica, náutica y tecnología aeroespacial y de propulsión (Gov.uk, 3 de agosto de 2012).

De los datos disponibles, se puede saber que el Reino Unido entre 1997 y 2016 ha exportado una determinada cantidad de insumos variables a la Argentina, que se han visto afectados por la política desenvuelta durante ese periodo de casi 20 años, posterior a la guerra del Atlántico Sur. De las exportaciones, hay Licencias Standard de Exportación Individual (SIEL, por sus siglas en inglés) que son licencias de exportación para bienes controlados, especificados para un exportador y un iportador. Los bienes incluidos aquí son aquellos consignados como de uso dual (civil o militar), de tortura (incluyendo drogas utilizadas para la inyección letal), fuentes radiactivas, bienes militares, tecnología electrónica (Gov.uk, 12 de septiembre de 2012). Conjuntamente, en el listado hay Licencias Abiertas de Exportación Individual (OIEL, por sus siglas en inglés),

Otros países que entran dentro de sanciones o embargo son Armenia, Azerbaiyán, Bielorrusia, Burma, Congo, Corea del Norte, Eritrea, Irán, Irak, Costa de Marfil, Líbano, Liberia, Libia, República de Guinea, Sierra Leona, Somalia, Sudán del Sur, Sudán, Siria, Zimbabwe. Todas se deben a la política exterior del Reino Unido y sus aliados, la búsqueda del mantenimiento de la paz, y la no proliferación de conflictos. 
una licencia emitida por la Organización de Control de Exportaciones (ECO, por sus siglas en inglés), que es mayormente flexible y diseñada para las necesidades del exportador, lo que permite múltiples envíos al exterior de ciertas mercancías a determinados países. Contempla el control de las tecnologías duales y materiales que podrían ser sensibles, pero dependiendo de la naturaleza del negocio y del exportador, facilitan su ejecución comercial (Gov.uk, 14 de agosto de 2012).

Todos los documentos hacen mención a criterios de exportabilidad, entre los que se destacan para los argentinos el número seis, a saber, el comportamiento del comprador en la comunidad internacional, la actitud ante el terrorismo, la naturaleza de sus alianzas internacionales y el respeto por la legislación internacional. También, otros factores como la incidencia de la exportación en cuestión sobre los intereses económicos, comerciales, industriales y sociales del país que las adquiere, y en especial los efectos sobre la economía británica, así como sus intereses comerciales e industriales, el efecto en las relaciones bilaterales y en la defensa colaborativa con aliados de los británicos, al igual que la protección estratégica de la industria.

\section{Metodología}

Se han relevado todos los documentos publicados por el Gobierno del Reino Unido en relación con las licencias de exportación a la República Argentina entre los 1997 y 2016. La selección de estos 19 años obedece a la disponiblidad de los datos y a que este periodo recorre presidencias con características políticas bien distintas y coyunturas internacionales que también lo fueron. Fundamentalmente, se parte de la premisa metodológica de que el Reino Unido ha tenido una política coherente en este sentido y que, en cambio, la Argentina ha variado su política exterior y su aproximación hacia las Malvinas y el reino británico, a pesar de que siempre, al menos formalmente, han reconocido el legítimo derecho soberano sobre los territorios en disputa con la potencia europea.

De todos los documentos relevados, se ha podido construir el argumento presente en este trabajo. No obstante, se hace acá otra salvedad metológica. El Reino Unido ha publicado distintos documentos en los que se publican datos con números concretos y descripciones de elementos aceptados o no para exportar al país suramericano y que se puede apreciar en los gráficos aquí presentados para ilustrar la evolución y materialización de una geopolítica de la limitación tecnológica. A pesar de ello, hay documentos que llamativamente poseen muy pocos datos o publican datos de exportaciones sobre un ítem particular. El Parlamento de ese país ha publicado enmiendas y correcciones a los documentos originales a partir de 2008. En ese sentido, para el presente trabajo, para evitar confusiones, se abordará el problema de la siguiente manera: en la descripción de los contenidos de 
la documentación oficial habrá una parte dedicada a las versiones originales y otra sección, a las correcciones desde 2008. Pero asumiendo que las cifras y datos corregidos han sido mejorados a partir de estos nuevos documentos, en las figuras se mostrará aquello que exponen estos últimos trabajos. Las licencias que hayan sido revocadas se tomarán en conjunto con las rechazadas por tratarse ambas de denegatorias.

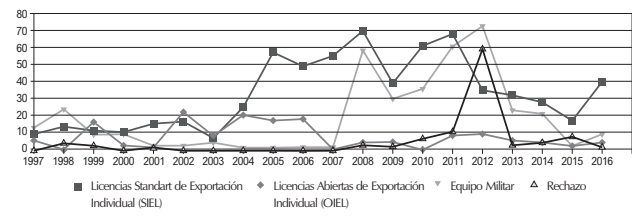

Figura 1. Licencia de exportación del Reino Unido a Argentina en Menem y Macri

Fuente: elaboración propia, a partir de datos oficiales del Reino Unido.

\section{Licencias de exportación}

\section{7}

Se exportaron bajo SIEL, detallado como sigue a continuación: armas de aire comprimido y de calibre menor, municiones para armas pequeñas $y$ deportivas, espectrómetros de masas, equipamiento electrónico, cámaras y sus componentes, sistemas de seguridad de informción, acelerómetros y componentes para el guiado, control y navegación, instrumentos y equipos inerciales. Bajo OIEL, se exportaron químicos y precursores, y software específico (Gov.uk, 14 de abril de 2014, 1997, pp. 22, 98). Se exportaron tam- bién nueve vehículos de combate para la misión argentina de las Naciones Unidas en Chipre. El documento aclara que las licencias de exportación están garantizadas solo en aquellos casos en los cuales no se pongan en riesgo los intereses británicos en Malvinas, ni a sus fuerzas de combate allí apostadas (SIPRI, 1997, pp. 115, 118) De hecho, todos los documentos subsiguientes aclaran esta situación, pero la cita será omitida; solo se aclarará si señala un dato novedoso.

\section{8}

Se exportaron bajo SIEL como sigue a continuación: armas de aire comprimido y de calibre menor, municiones para armas pequeñas y deportivas, municiones inertes y espoletas, componentes o vehículos aéreos livianos, equipamiento electrónico o componentes para vehículos aéreos, aleaciones, equipamiento de telemetría y telecontrol, cámaras o componentes relativos, instrumental y equipo de navegación. También se importaron armamentos menores. No obstante, un SIEL fue rechazado para su exportación, pues figuraba en la lista de ítems militares: placa blindada para protección (Gov.uk, diciembre de 2015, 1998, pp. 11, 129).

\section{9}

Se exportaron bajo SIEL así: armas de aire comprimido y de calibre menor, municiones inertes y espoletas, vehículos terrestres y componentes, equipamiento naval, equipo para entrenamiento militar y simulación de 
combate, bismuto, cámaras y componentes y un ítem S1P1 que no se encuentra detallado en el listado de ítems de exportación del Reino Unido. Bajo OIEL se exportó software para criptoanálisis, equipamiento y software para seguridad de información, equipamiento acústico, instrumentos y equipos inerciales, acelerómetro y giróscopos. También se exportaron componentes fluorados, materiales compuestos de fibra de carbono o vidrio, polímero no fusible, materiales compuestos de fibra de carbono o vidrio en forma de tubo, computadoras electrónicas y ensamblajes electrónicos, computadoras digitales, computadora sistólica, neural u óptica, acelerómetros, giroscopios o sensores de velocidad angular, equipo o sistema de medición inercial, rastreador de estrellas, sistema de navegación global satelital, altímetros aerotransportables de entre 4.2 y $4.4 \mathrm{Ghz}$., equipamiento de telecomunicaciones, sistemas y componentes, acelerómetro lineal para navegación inercial o sistemas de guiado incluyendo misiles, giroscopios usables en sistemas misilísticos o vehículos aéreos no tripulados que no excedan un alcance de 300 kilómetros, instrumental, equipo de navegación para sistemas inerciales, brújula giróscopica, sistema de control de navegación aérea, set de guiado usable en misiles, turbina de gas aéreo, motor turbina marino, ensamblajes o componentes especiales para países que no hayan suscrito el Tratado de
Wasenaar o que no sean parte de la Unión Europea, o un fabricante desconocido, motor estatorreactor, motor estatorreactor de combustión supersónica, motor turbojet o turbofan, motor pulsorreactor, aparatos para regular la combustión de motores usable en misiles. Fueron rechazadas las exportaciones de equipamiennto para control del fuego, alarmas y de prevención para uso militar, equipos de prueba para componentes espaciales, para armas cinética, manuales y bibliografía especializada sobre bombas, torpedos, cohetes y misiles, y otro tipo de tecnología (Gov.uk,1999, p. 21).

\section{0}

Se exportaron bajo SIEL como sigue a continuación: diez ítems en total, correspondiendo ocho a uso militar o dual y el resto a otros usos. De lo exportado, sin tanto detalle como los informes anteriores publicados ${ }^{2}$, se encuentran armaduras, componentes para destructores, componentes para asientos eyectables, componentes para equipo de comunicación militar, componentes para motores navales, equipamiento para uso de montaje flotante marino, montajes flotantes marinos, tubos de aleación de metal, equipos de comunicación militar, televisores resistentes a la radiación, cámaras y lentes y escopetas. Bajo OIEL se exportaron dos ítems, incluyendo equipamiento para criptografía y tecnología para uso criptográfico (SIPRI, 2000, p. 19).

De aquí en adelante no hay informes con tanto nivel de detalle en las licencias. 
2001

Se exportaron bajo SIEL así: 15 ítems en total, correspondiendo ocho a uso militar o dual, cinco a otros ítems y dos a militares y otros. De lo exportado, se encuentran armaduras, armaduras o chalecos antibala de uso civil, componentes para fragatas, componentes para motores aéreos, software criptográfico, armas de fuego desactivadas para simuladores de entrenamiento, patógenos humanos, equipo de detección de explosivos, cilindros de aleación de metal, escopetas y precursores químicos tóxicos. Se exportaron también containers militares, traileres militares y vehículos utilitarios de uso militar. Se rechazó el pedido de equipamiento electrónico para aeronaves. Bajo OIEL se exportó un ítem, correspondiente a equipamiento sumergible (SIPRI, 2001, p. 20).

\section{2}

Se exportaron bajo SIEL, detallado como sigue a continuación: 16 ítems en total, correspondiendo 14 a uso militar y 2 correspondiente a otros ítems. Se exportaron componentes para asientos eyectables, componentes para motores aéreos militares, componentes para aviones de entrenamiento militar, componentes para motores navales, armamento de fuego desactivado para simuladores de entrenamiento, equipamiento para el uso de motores aéreos, componentes generales para barcos, escopetas, tecnología para el uso de motores aéreos para uso militar, formación de hidrófono remolcable y precursores químicos tóxicos. Bajo OIEL se exportaron 22 ítems, siendo estos: equipamiento inercial, equipamiento para criptografía, acelerómetros, giróscopos y sus componentes, equipamiento para posicionamiento marítimo, tecnología productora de toxinas, componentes para asientos eyectables y otros para aviones de combate, componentes para submarinos y navales y su armamento relacionado y munición para armas pequeñas (SIPRI, 2002, pp. 28 y 29).

\section{3}

Se exportaron bajo SIEL, como sigue a continuación: siete ítems en total, correspondiendo tres a uso militar y cuatro a otros. Se exportaron componentes para motores de avión, computadora digital, equipamiento criptográfico, hierro, espectrómetro de masas, una licencia temporal para visualizador head-up para aviones militares y escopeta. Bajo OIEL se exportaron ocho ítems, entre los que están equipo criptográfico, magnetómetros, software para criptografía y otros componentes, cámaras para imágenes y formación de hidrófono remolcable (SIPRI, 2003, p. 33).

\section{4}

Se exportaron bajo SIEL así: 10 ítems y 15 temporarios. Desde OIEL, 15 y 5 temporarios (SIPRI, 2004, p. 27). El documento aclara que las licencias están solamente garatizadas para aquellas exportaciones que, al tiempo de la aplicación de los argentinos para el 
requerimiento de estas, no pongan en riesgo, en un futuro previsible, la seguridad de los territorios de ultramar del Reino Unido en el Atlántico Sur, o a las fuerzas militares que allí operan (Gov. uk, 2004, p. 180).

\section{5}

Se exportaron bajo SIEL, detallado como sigue a continuación. 57 ítems y bajo OIEL 17 (SIPRI, 2005, p. 22). EI documento aclara que las licencias están solamente garatizadas para aquellas exportaciones que, al tiempo de la aplicación de los argentinos para el requerimiento de estas, no pongan en riesgo, en un futuro previsible, la seguridad de los territorios de ultramar del Reino Unido en el Atlántico Sur, o a las fuerzas militares que allí operan (SIPRI, 2005, p. 71).

\section{6}

Se exportaron bajo SIEL Como sigue a continuación: 49 ítems y 18 bajo OIEL (SIPRI, 2006, p. 32). El documento aclara que las licencias están solamente garatizadas para aquellas exportaciones que, al tiempo de la aplicación de los argentinos para el requerimiento de las mismas, no pongan en riesgo, en un futuro previsible, la seguridad de los territorios de ultramar del Reino Unido en el Atlántico Sur, o a las fuerzas militares que allí operan (SIPRI, 2006, p. 74).

\section{7}

Este informe, contrariamente a los anteriores, no da detalles específicos de
SIEL y OIEL para cada Estado y para Argentina en particular. Sin embargo, detalla el tipo de exportación: 53 escopetas y 2 rifles o carabinas (SIPRI, 2007, pp. 96-97), siendo estos 55 ítems SIEL (Gov.uk, 12/2015). El informe no aporta otros datos sobre Argentina.

\section{8}

Este informe continúa con el formato del anterior, sin detalles específicos sobre SIEL o OIEL para cada país, pero sí publica un total de 84 escopetas (SIPRI, 2008, p. 92) que corresponden a SIEL (Gov.uk, diciembre de 2015).

El informe corregido señala que se otorgaron 70 licencias SIEL, de las cuales 57 eran para uso militar y 13 de uso no militar. Las de uso militar son: escudos balísticos, componentes para aeronaves de combate, componentes para fragatas, componentes para presurización de aire de aeronaves militares, componentes para entrenamiento militar de aeronaves, componentes para aviones de transporte militar, componentes para escopetas, escopetas y componentes para equipamiento de comunicación militar (Gov.uk, 2008b, pp. 30 y 31). Las de uso no militar son: equipamiento para biotecnología, componentes resistentes a la corrosión química, fluídos de enfriamiento electrónico, equipamiento para criptografía, fibras y filamentos, patógenos humanos, cámaras de TV para radiación, equipamiento para pruebas de vibración (Gov.uk, 2008b, p. 31). 
Se otorgaron bajo OIEL cuatro licencias, dos de ellas revocadas y una rechazada. Las licencias fueron para cojinetes antifricción, software habilitador de equipos de comunicaciones para funcionamiento como equipamiento militar (revocado), software criptográfico y software para equipos de comunicación militar (revocado). Fue rechazada la licencia para escudos balísticos, armadura corporal, armadura corporal de uso civil, componentes para armadura y cascos militares (Gov.uk, 2008b, p. 31).

\section{9}

Este informe continúa con el formato del anterior, sin detalles específicos sobre SIEL o OIEL para cada país, pero sí publica un total de 27 escopetas (SIPRI, 2009, p. 41) que corresponden a SIEL (Gov.uk, diciembre de 2015).

El informe corregido señala que se otorgaron 39 licencias SIEL, de las cuales 29 eran de uso militar y 10 para uso no militar. Las de uso militar fueron componentes para rifles de asalto, componentes para aviones de combate, componentes para asientos eyectables, componentes para aviones de entrenamiento militar, componentes para motor naval, componentes para pistolas semiautomáticas, componentes para ametralladoras, componentes para barcos, equipamiento para señal de socorro, motores navales, escopetas, munición para armas pequeñas, y munición de entrenamiento para armas pequeñas. Las de uso no militar fueron equipamiento para crip- tografía, fibras y filamentos, cámaras para imágenes, uranio natural, niquel procesado, equipamiento sumergible, torio, toxinas varias y zirconio (Gov.uk, 2009b, p. 33).

Se otorgaron bajo OIEL cuatro licencias, correspondientes a equipamiento para criptografía, componentes para motores navales (revocado) y tecnología de software naval (revocado), y software criptográfico (Gov.uk, 2009b, p. 33).

\section{0}

Este informe continúa con el formato del anterior, sin detalles específicos sobre SIEL o OIEL para cada país, pero sí publica un total de 28 rifles o carabinas (SIPRI, 2010, pp. 45-47) que corresponden a SIEL (Gov.uk, diciembre de 2015).

El informe corregido señala que se otorgaron 61 licencias SIEL, de las cuales 35 eran de uso militar y 26 para uso no militar. Las primeras fueron armamento aéreo, componentes para destructores (revocado), componentes para asientos eyectables (revocado), componentes para radares militares (revocado), componentes para aeronaves de entrenamiento, componentes para helicópteros militares (revocado), componentes para escopetas, componentes para rifle de francotirador, equipamiento para montura de armamento, radares militares (revocado), escopetas, armas deportivas, montura para miras. Las segundas fueron patógenos animales, químicos, 
equipamiento para criptografía, fibras y filamentos, cámaras para imágenes, productos con helio, productos con plutonio 239, software para equipos criptográficos y formación de hidrófono remolcable. Una licencia para uso militar fue rechazada, correspondiente a componentes electrónicos (Gov.uk, 2010b, p. 33).

Bajo OIEL fueron pedidos y rechazados: formación de hidrófono remolcable e hidrófonos (Gov.uk, 2010b, p. 34).

\section{1}

Este informe continúa con el formato del anterior, sin detalles específicos sobre SIEL o OIEL para cada país, pero sí publica un total de tres rifles deportivos (SIPRI, 2011, p. 50) que corresponden a SIEL (Gov.uk, diciembre de 2015).

El informe corregido señala que se otorgaron 68 licencias SIEL, de las cuales 60 eran de uso militar y 8 para uso no militar. Las primeras fueron escudos balísticos antidisturbios, componentes para aviones de combate (revocado), componentes para barcos de combate (revocado), componentes para motores de aeronave (revocado), componentes para uso militar terrestre de aeronaves (revocado), componentes para respiración de tripulación, componentes para guiado y navegación (revocado), componentes para aeronaves (revocado), componentes para aeronaves de entrenamiento (revocado), componentes para aeronaves de transporte militar (revocado), componentes para motores navales (revocado), componentes para armas deportivas, componentes generales para aeronaves militares, componentes para uso terrestre de aeronaves (revocado), munición para armas pequeñas y armas deportivas. Las de uso no militar fueron patógenos animales, componentes para detección de gases tóxicos, equipamiento resistente a la corrosión, material criptográfico, cámaras para imágenes. Posteriormente, fue revocada la licencia para componentes de armadura corporal (Gov.uk, 2011b, pp. 31 y 32).

Se otorgaron bajo OIEL ocho licencias y una fue revocada. Las licencias fueron para equipamiento criptográfico, patógenos animales, sensores para hidrófonos, equipo inercial, componentes para equipos inerciales, selladores para aeronaves y tecnología para equipos militares de comunicación (revocado) (Gov.uk, 2011b, p. 33).

\section{2}

Este informe destaca que se exportaron 44 rifles deportivos correspondientes a SIEL (SIPRI, 2012, p. 57). EI documento se destaca para la Argentina porque empieza a mencionarla más ampliamente por la cuestión Malvinas en la relación bilateral, en la primera página.

En abril de 2012, la Secretaría de Negocios anunció que el Reino Unido no otorgará a la Argentina más licencias de exportación para mercancías militares o de uso dual 
para usuarios finales militares, salvo excepecionales circunstancias, con el propósito de asegurarse de que ninguna exportación británica pueda ser utilizada por la Argentina para dañar los intereses económicos de las Islas Malvinas. Por lo tanto, 43 licencias fueron subsecuentemente revocadas, pero las licencias de exportación para puro uso comercial o privado han continuado. (SIPRI, 2012, p. 1)

El 26 de abril de 2012, el secretario de egocios informó al Parlamento los cambios en la política del Reino Unido hacia las licencias de exportación relacionadas con usuarios finales militares en la Argentina. Declaró el Secretario que se cambió la política de tráfico y corretaje de mercancías controladas y tecnología militar. La política previa, que data de 1998, requería de la denegatoria de licencias para la exportación y el comercio que fuera para las capacidades militares de los argentinos, pero permitía licencias de algunos bienes que mantenían las capacidades existentes. En la práctica esto significaba la autorización para la exportación y comercio de componentes para el mantenimiento de dichas capacidades. El Gobierno británico ha reformulado esta política a la luz de las recientes acciones del Gobierno argentino para dañar los intereses económicos de los isleños de las Malvinas.

El secretario inglés declaró que su Gobierno está determinado en asegurar que ninguna licencia de exportación o comercio tenga el potencial de ser uti- lizado por el país sudamericano para imponer un bloqueo económico sobre las islas en disputa o inhibir los reclamos de sus legítimos derechos para desenvolver su propia economía.
Nuevas restricciones sobre la ex- portación y el comercio de bienes que requieren licencia para los mi- litares argentinos serán introducidas con efecto inmediato. En el futuro, ninguna licencia será otorgada para uso militar, o cualquier mercancía de uso dual $[. .$.$] a menos que exista$ una situación excepcional. (SIPRI, 2012, p. 7)

El documento explica que 36 licencias estándar y 6 licencias abiertas fueron revocadas a partir de esta nueva política. Conjuntamente, se afirma que esta nueva modalidad no aplica para aquellos usuarios finales que no son militares. Destaca el informe que se aprobaron 35 licencias SIEL por un total de $£ 6.226 .625$ y 9 fueron rechazadas (SIPRI, 2012, p. 17). Lo exportado hacia la Argentina corresponde a las categorías ML1 y ML3, rifles y municiones deportivas (SIPRI, 2012, p. 76).

El informe corregido señala que se otorgaron 35 licencias SIEL, de las cuales 23 eran de uso militar y 12 para uso no militar. Las de uso militar fueron componentes para motores de aeronaves (revocado), componentes para aviones militares (revocado), munición para armas pequeñas, y armas deportivas. Las de uso no militar fueron patógenos animales, químicos para farmacéutica, componentes para re- 
actores nucleares, equipamiento para criptografía, cámara para imágenes, televisores para radiación, software criptográfico, equipamiento solar apto para uso espacial, equipamiento para biotecnología.

Fueron rechazadas nueve licencias de exportación de uso militar. Los rechazos correspondieron a componentes para asientos eyectables, componentes para equipamiento de aeronaves operativas en áereas confinadas, componentes para motores de aeronave, componentes para radares militares, componentes para apoyo aéreo de aeronaves, componentes para motores navales, componenes navales, tecnología para combate aéreo.

Además, fueron revocadas 36 licencias para componentes de aviones, componentes para barcos de combate, componentes para destructores, componentes para asientos eyectables, componentes para aviones militares, componentes para uso terrestre de aviones militares, componentes para guiado y navegación, componentes para radares militares, componentes para apoyo aéreo, componentes para aviones de entrenamiento, componentes para aeronaves de transporte militar, componentes para helicópteros militares, componentes para motores navales y radares militares. Por último, fueron revocados componentes para armaduras corporales (Gov. uk, 2012b, pp. 33-35).

Desde OIEL se aprobaron nueve licencias para equipamiento criptográfico, hidrófonos, armas deportivas, componentes para aeronaves militares (revocado), componentes para navegación marina, software criptográfico y acelerómetros. Fueron rechazadas cinco licencias para componentes para naves de combate aéreo, equipamiento militar de respiración de tripulación aérea y componentes para naves militares varios. Fueron revocadas seis licencias para software de comunicación militar, componentes para motores navales, material criptográfico, tecnologías de comunicación militar, componentes para aviones militares (Gov.uk, 2012b, pp. 36 y 37$)$.

\section{3}

El documento señala que se exportaron a la Argentina 619 rifles deportivos correspondientes a la categoría SIEL (Gov. uk, 2013, p. 55). Este informe ratifica aquello que se establecía en el del año anterior en cuanto a la nueva política de restricción para la Argentina, en tanto se trate de bienes de uso dual o cuyo usuario final sea militar (Gov.uk, 2013, p. 38). También se documenta la licencia de exportación SIEL de 20 ítems para armas de aire comprimido y de calibre menor (ML1), dos ítems para municiones inertes y espoletas (ML3) y un ítem para bombas, torpedos, cohetes, misiles u otros elementos relacionados como equipamiento para guiado y navegación, o sistemas de protección de vehículos aéreos contra misiles (ML4), lo que constituye la excepción a la política explícitamente aludida por las autoridades responsables británicas (Gov.uk, 2013, p. 78). 
El informe corregido señala que se otorgaron 32 licencias SIEL, de las cuales 22 eran para uso militar y 10 para uso no militar. Las primeras fueron componentes para armas deportivas, munición para armas deportivas, armas deportivas y miras para armamento deportivo. Las segundas fueron equipos para criptografía, patógenos humanos, cámaras para imágenes, aleación de metal, software criptográfico y equipamiento sumergible. Fueron rechazadas tres licencias de componentes tanto para criptografía, como para aviones militares, así como equipamiento solar apto para uso espacial (Gov.uk, 2013b, pp. 32-24).

Se otorgaron desde OIEL cinco licencias para lásers, gatillos, tecnología militar para artillería, radares o misilística, software para equipo inercial e hidrófonos (Gov.uk, 2013b, p. 35).

\section{4}

El documento no da cuenta de ninguna licencia de exportación a la Argentina. Este informe ratifica aquello que se establecía en el del año anterior en cuanto a la nueva política de restricción para la Argentina, en tanto se trate de bienes de uso dual o cuyo usuario final sea militar (SIPRI, 2014, p. 35).

El informe corregido señala que se otorgaron 28 licencias SIEL, de las cuales 20 eran de uso militar y 8 para uso no militar. Las primeras fueron escudos balísticos antidisturbios, componentes para cascos militares, componentes para rifle de francotirador, componentes para arma deportiva, monturas para armas, munición para armas pequeñas, rifle de francotirador, armas deportivas y escopetas deportivas. Las segundas fueron equipos para protección civil, equipamiento para agentes de control de disturbios, productos con deuterio, equipamiento criptográfico, cámaras para imágenes, productos con radio-226, productos con torio, semiconductores, software para criptografía y detector de gas tóxico. Fueron rechazados componentes para equipos de comunicación militar y cámaras para imágenes (Gov.uk, 2014b, pp. 33 y 34).

Desde OIEL se otorgaron cuatro licencias para patógenos animales, componentes para sonar, transductores de presión y software para equipo inercial. Fue rechazada la licencia para hidrófono remolcable y vehículos militares de combate de Sudáfrica (Gov. uk, 2014b, p. 35).

\section{5}

El documento no da cuenta de ninguna licencia de exportación a la Argentina. Este informe ratifica aquello que se establecía en el del año anterior, en cuanto a la nueva política de restricción para la Argentina, mientras se trate de bienes de uso dual o cuyo usuario final sea militar (SIPRI, 2015, p. 31).

El informe corregido señala que se otorgaron 17 licencias SIEL, de las cuales una era de uso militar y 8 para 
uso no militar. La primera fue para armas deportivas. Las segundas fueron detectores de explosivos de uso civil, componentes para reactores nucleares, componentes con helio, fibras y filamentos, cámaras para imágenes, equipo de seguridad informática, aleación metálica, generador de neutrones, material de níquel, software para seguridad informática, software para generador de rayos $X$, tecnología para generación de rayos $X$, acelerador de rayos $X$, escopetas deportivas e hidrófonos. Fueron rechazadas $4 \mathrm{li}$ cencias de uso militar, entre las cuales se encuentran equipamiento para test balístico, software y componentes, equipamiento para la producción de munición de armas pequeñas y componentes para aviones militares (Gov. uk, 2015b, pp. 32 y 33).

Desde OIEL se aprobaron dos licencias para componentes de seguridad informática e hidrófonos. Fueron rechazados cuatro ítems, entre los cuales se encuentran equipo de protección civil, miras para armas, componentes para seguridad informática y material de apoyo de aeronaves militares (Gov. uk, 2015b, p. 34).

\section{6}

El documento evidencia 40 licencias SIEL de exportación, de las cuales 6 son categorizadas como de uso militar, 32 no militar y 2 para uso dual. Las SIEL nomencladas como militares corresponden a 4 licencias para armas de aire comprimido y de calibre menor, una licencia para municiones inertes y espoletas, y una para placa blindada para protección. En el documento están especificados dentro de estas licencias varios ítems: armadura blindada, componentes para armaduras, cascos militares, municiones para armas pequeñas, escopetas deportivas, munición para escopeta deportiva, visor nocturo y mira de precisión para armas de fuego. De los ítems no militares constan las licencias para componentes de reactores nucleares, componentes de deuterio, aparatos para iniciar explosivos, cámaras, equipamiento para seguridad informática, software para equipamiento de seguridad informática, escopetas deportivas, tecnología para generación de rayos $\mathrm{X}$ y equipamiento de rayos $\mathrm{X}$. De uso dual, por último, las licencias fueron para visor directo de imágenes, cámaras, armas deportivas y escopetas deportivas. Fue rechazada una licencia de uso militar, por ser controlada por regímenes de control de armas de destrucción masiva (Gov.uk, 2016, pp. 36 y 37$)$.

Desde OIEL se exportaron equipos y software de tecnologías de información, formación de hidrófono remolcable, material para sellado de aviones, equipamiento de navegación, guiado y control, equipamiento inercial, equipamiento acústico para fondos marinos, componentes para equipos inerciales, equipamiento inercial, magnetómetros, sistema de posicionamiento marino y equipamiento para sonar (Gov.uk, 2016, p. 38). 


\section{Un nuevo gobierno, ¿una nueva relación?}

El entonces primer ministro del Reino Unido, David Cameron, llamó por teléfono a su par electo en las elecciones presidenciales de 2015, en las que Mauricio Macri resultó ganador por una ajustada segunda vuelta. En dicha comunicación, Cameron le expresó sus felicitaciones y acordaron que se abría una oportunidad para fortalecer las relaciones bilaterales, y desarrollar las inversiones y el comercio existente. El primer ministro dio apoyo a las reformas económicas de mercado para llevar adelante y las relaciones de libre comercio entre la Unión Europea y el Mercosur (Gov.uk, 26 de noviembre de 2015).

El primer ministro, Cameron, se encontró posteriormente con el presidente en funciones, Mauricio Macri, y ambos acordaron que había una oportunidad de embarcarse en un nuevo capítulo en las relaciones entre ambos países. Hablaron de las reformas económicas, del comercio y las inversiones, y de las islas Malvinas. Discutieron cómo el país europeo podría ayudar a la Argentina en los planes de reformas en la economía, particularmente en energía, transparencia y ciencia. De acuerdo con ambos mandatarios, las reformas económicas en la Argentina podrían llevar a grandes oportunidades de negocios para los inversores británicos en infraestructura, petróleo, gas, minería, agroindustria (Gov.uk, 21 de enero de 2016), es decir, varios de los sectores estratégicos de la economía del país sudamericano.
Posteriormente, al calor de los sucesos de política exterior y que le dieron un color diferente a las relaciones bilaterales, el Gobierno británico emitió un comunicado de prensa en el que celebraba que
[...] el Reino Unido recibió con un rotundo éxito la visita de la Arma- da Argentina en Julio de 2016 me- diante el ARA Libertad a la ciudad de Liverpool. La visita fue parte del reinicio de las relaciones con la Argentina bajo la administración Macri. La última vez que esta nave de entrenamiento visitó el Reino Unido fue en 2003. (Gov.uk, 19 de diciembre de 2016)

Desde el Ministerio de Relaciones Exteriores británico, tras una sensible mejora en las relaciones con los argentinos desde la elección de Macri como primer mandatario -según consigna la web parlamentaria-, "se dio un gran paso tras una década de dificultades dado el enfoque aislacionista del gobierno anterior" (Gov.uk, 12 de septiembre de 2016), aludiendo a Cristina Fernández de Kirchner. Se destaca que no se producía una visita semejante desde 2009, cuando Fernández de Kirchner se encontraba en su primer mandato, y que el diálogo significó un gran avance para tender vínculos aéreos con el territorio argentino. Asimismo, recalcó el derecho de los habitantes de las islas a permanecer siendo ciudadanos británicos.

Al día siguiente, ambas partes hicieron una declaración conjuntaqueabarcaba 
varios de los tópicos de la agenda bilateral del nuevo Gobierno de Macri y el de Cameron. Concretamente, en lo relacionado con el objeto de estudio del presente trabajo, se destacas el punto 3 de cooperación en Ciencia y Tecnología, para la innovación y el mejoramiento productivo, así como la colaboración en materia de instituciones científicas y antárticas: todos temas sensibles y estratégicos para la política exterior y el desarrollo argentino, cuya posición ante una potencia como el Reino Unido es de mayor debilidad. Conjuntamente, en el punto 8 referente a Seguridad y Defensa, se acordó confrontar los desafíos globales a la paz y la estabilidad mundial, y la cooperación de las Fuerzas Armadas de ambas naciones. El punto más importante de la relación bilateral (punto 10) establece la cooperación y el diálogo entre ambas partes. "En este contexto fue acordado tomar las medidas apropiadas para remover los obstáculos que limitan el crecimiento económico y el desarrollo sustentable de las Islas Malvinas, incluyendo el comercio, la pesca, el transporte y la explotación hidrocarburífera" (Gov. uk, 14de septiembre de 2016). Esto rompe con la política de los Kirchner de no permitir ni facilitar el enclave colonial en territorio argentino y la explotación de sus recursos y su espacio geográfico. El Estado europeo se encargó de aclarar que el diálogo y la soberanía no estaban en agenda, pues "nada de la discusión o la declaración afecta a la soberanía de las islas y el Reino Unido continúa absolutamente claro en su apoyo a los derechos de los isleños" (Gov.uk, 15 de septiembre de 2016).

\section{Conclusiones y evidencias}

La evidencia muestra que la política del Reino Unido fue limitar tecnológicamente a la Argentina en materia militar, pero no cortar toda transferencia. No obstante, los datos disponibles conseguidos muestran que dicha limitación no era total, sino segmentada y condicionada a la política de control británica, como puede observarse desde 1997. Pero la guerra ocurrió en 1982 y tras la victoria de la potencia europea distintas aproximaciones a la relación bilateral ocurrieron desde Argentina y motivaron las políticas tecnológicas inglesas. El Gobierno de Alfonsín (19831989), heredero de las políticas de la dictadura militar que llevaron a la guerra en el Atlántico Sur, vio reducida su acción política, limitada por crisis políticas y económicas internas. El Gobierno de Menem (1989-1999) comenzó a gobernar en la transición Posguerra Fría. El mundo adoptaba políticas liberales, democratización, apertura de las economías: otro escenario institucional y geopolítico. En 1990 se restablecieron formalmente las relaciones bilaterales entre los británicos y los argentinos, y los canales de comunicación diplomática se reestablecieron, siempre con las limitaciones correspondientes, dado el conflicto por las Malvinas, siempre abierto. En efecto, esto puede corroborarse a partir de los documentos de 1997 y en adelante con los datos aquí presentados en cuanto a las exportacio- 
nes, tanto de material militar completo, como de tecnologías de uso dual.

También se podrán observar unos movimientos ascendentes de las figuras presentadas en este trabajo, cuando la recuperación económica argentina tuvo lugar hacia la mitad de la década de 2000, y cómo a partir de la década de 2010, cuando se disparan nuevamente conflictos bilaterales por disputas en relación con las Malvinas caen las exportaciones y suben los rechazos para las licencias de exportación. La incógnita para un próximo trabajo será estudiar qué pasó con el Gobierno de Macri, hasta llegar al final de su mandato (termina formalmente en 2019), cuya política exterior dio un giro hacia Gran Bretaña y las Malvinas, y dicho dato es reconocido por los propios documentos publicados por el Parlamento británico.

Sin embargo, se pueden obtener algunas conclusiones preliminares a partir del informe de 2016, cuyos datos sugieren un cambio. En efecto, durante el primer año de gestión del presidente Macri la exportación del Reino Unido a la Argentina en tecnologías de uso dual y militar ha mostrado un incremento significativo, después de un par de años en los que las sumas totales estaban en cero. ¿Se mantendrán estas cifras en el tiempo? ¿Continuará creciendo el número de exportaciones de tecnologías sensibles a la Argentina durante esta administración? Es claro que habrá que esperar los datos oficiales publicados por el Gobierno británico. No obstante, creemos que el cambio de política internacional de Macri sí muestra que existió y existe hoy -en menor grado- una geopolítica de restricción tecnológica.

El Gobierno de Macri ha mostrado claras señales a Londres sobre sus alianzas internacionales, sobre la posición del nuevo Gobierno argentino con respecto a las Malvinas y al Atlántico Sur que, si bien en lo formal no se renuncia al reclamo de soberanía, es claro que no se ejercerán presiones sobre los isleños ni los intereses británicos para hacer costoso el sostenimiento económico del enclave colonial. ¿Cuál ha sido el resultado inmediato?, un aumento de las licencias de exportación.

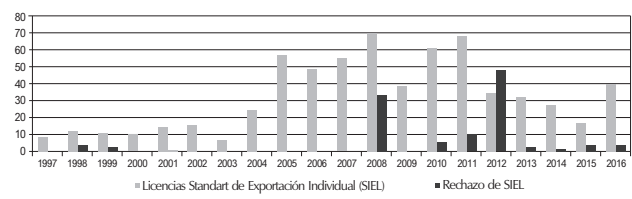

Figura 2. Licencias SIEL y rechazo del Reino Unido a la Argentina

Fuente: elaboración propia, a partir de datos oficiales del Reino Unido.

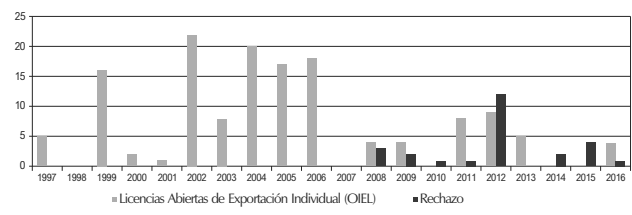

Figura 3. Licencias OIEL y rechazo del Reino Unido a la Argentina

Fuente: elaboración propia, a partir de datos oficiales del Reino Unido. 


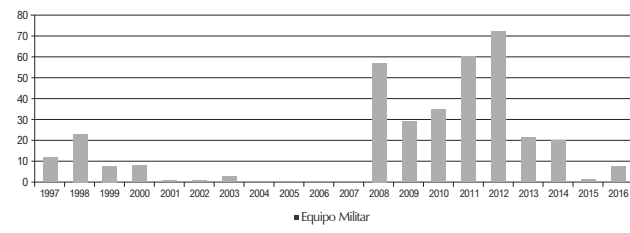

Figura 4. Exportación equipo militar del Reino Unido a la Argentina

Fuente: elaboración propia, a partir de datos oficiales del Reino Unido.

El gasto militar argentino ha descendido sistemáticamente tras la guerra de 1982, y continuó en la década de 1990 en sintonía con una nueva política exterior basada en la inserción internacional alineada con el nuevo orden mundial liberal hegemonizado por Estados Unidos, tras la desaparición de la Unión Soviética. También las importaciones de armamento han descendido sistemáticamente.

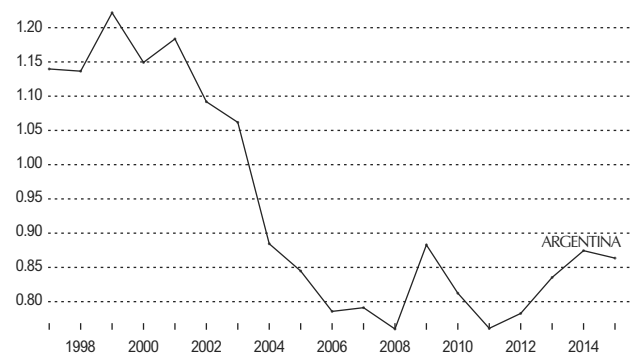

Figura 5. Gasto militar en porcentaje del producto interno bruto (1997-2015)

Fuente: Banco Mundial (2016).

Teniendo en cuenta los datos aquí aportados, iqué se puede concluir? Que existió una política de restricción tecnológica hacia los argentinos que se describe en los documentos del Gobierno del Reino Unido, en los cuales explícitamente se hace mención a la política de proteger los intereses de este país en las Malvinas, y no poner

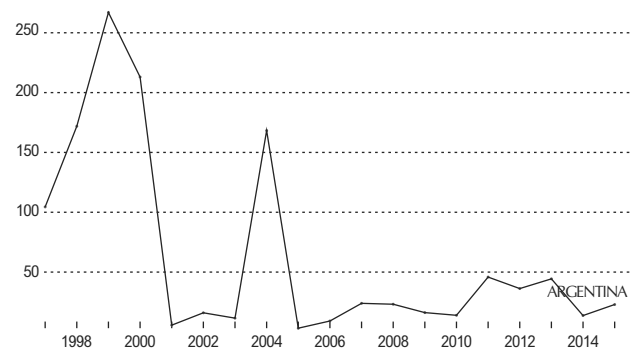

Figura 6. Importaciones de armas a precios constantes en US\$ de 1990 (1997-2015)

Fuente: Banco Mundial (2016).

en peligro a la población, las tropas militares ni el territorio con cualquier transferencia directa de material bélico o tecnologías de uso dual que podrían ser utilizadas militarmente contra los objetivos que esta política pública decide proteger en el Atlántico Sur. Pero si la política del gobierno de turno es una como la de Menem -que propicia una buena relación con los estadounidenses y sus aliados europeos-, la posibilidad de adquirir tecnologías británicas por parte del Gobierno argentino son muy superiores a las que tiene un Gobierno como el de Cristina Fernández de Kirchner, que genera una política mancomunada con los países de la región para dificultar el abastecimiento de las islas Malvinas, por lo cual, y en consecuencia, las limitaciones a las exportaciones son absolutas.

¿Por qué en este trabajo ha sido denominado geopolítica de la limitación tecnológica? Porque se trata de una política con anclaje territorial, con construcción de imaginarios geopolíticos basados en percepciones estratégicas sobre la Argentina, relacionadas con la historia militar reciente, pero 
también porque existe una acción planificada para evitar capacidades tecnológicas que puedan incrementar el poder de fuego argentino en el Atlántico Sur. Esa política está institucionalmente organizada con el control del Estado para la exportación de tecnologías y la participación activa en organismos institucionales internacionales. Así, el Parlamento de Londres limita la exportación al Gobierno en Buenos Aires, pero también destaca la participación diplomática del país sudamericano en organismos de control de armas de destrucción masiva y no proliferación. Es decir, la estrategia es global y local, a partir de instituciones nacionales e internacionales, respectivamente. La geopolítica británica consiste en debilitar la posibilidad argentina de conseguir tecnologías que puedan afectar sus intereses, en un doble juego que los compele a participar en el juego liberal del control internacional, siempre en consonancia con las políticas de los países centrales; asimismo, limita directamente los intereses en la relación bilateral. Los datos muestran que esta política ha sido muy efectiva.

\section{Referencias}

Agnew, J. (1995). Mastering space. Hegemony, territory and international political economy. Nueva York: Routledge.

Agnew, J. (2005). Geopolítica. Una revisión de la política mundial. Madrid: Trama.
Blinder, D. (2016). Sobre la cuestión dual: apuntes para pensar la periferia. Grupo de Estudios en Seguridad Internacional [GESI]. Universidad de Granada. Recuperado de http://www.seguridadinternacional.es/?q=es/content/ sobre-la-cuesti\%C3\%B3n-dualapuntes-para-pensar-la-periferia.

Dodds, K. (2007). Geopolitics: a very short introduction. Oxford: Oxford University Press.

Lacoste, Y. (2011). Investigación sobre el bombardeo de los diques del río Rojo (Vietnam, verano de 1972). Método de análisis y reflexiones de conjunto. Revista Geopolítica(s), 2(2), 313-337.

Lacoste, Y. (2011). Del razonamiento geográfico, táctico y estratégico al razonamiento geopolítico: los comienzos de Herodote. Revista Geopolítica(s), 2(2), 339-342.

La Nación (21 de enero de 2012). "La Argentina no intimida a nadie, sólo reclama un derecho irrenunciable", sostuvo Randazzo. La Nación. Recuperado de http://www.lanacion. com.ar/1442349-el-canciller-ingles-pidio-al-gobierno-detenersus-intentos-de-intimidacion-a-loshabitantes-

Martin, L. (1992). Institutions and Cooperation: sanctions during the Falkland Islands Conflict. International Security, 16(4), 143-178.

Mazzucato, M. (2013). The entrepreneurial state: debunking public vs. private sector myths. London: Anthem Press. 
Parliamente.uk (26 de abril de 2012). Written Ministerial Statements. Recuperado de http://www. publications.parliament.uk/pa/ cm201212/cmhansrd/cm120426/ wmstext/120426m0001. htm\#12042672000002

Phythian, M. (2000). The politics of british arms sale since 1964: "to secure our rightful share". Manchester: Manchester University Press.

Ruttan, V. (2006). Is War Necessary for Economic Growth? Military Procurement and Technology Development. Oxford: Oxford University Press.

Stockholm International Peace Research Institute [SIPRI] (2015). TOP 100 arms-producing and military services companies, 2014. Recuperado de http://books.sipri.org/files/ FS/SIPRIFS1512.pdf

Gov.uk (3 de agosto de 2012). Current arms embargoes and other restrictions. Recuperado de https://www. gov.uk/guidance/current-arms-embargoes-and-other-restrictions

Gov.uk (11 de septiembre de 2012). Brokering (trade) of dual-use items. Recuperado de https://www.gov. uk/guidance/brokering-trade-of-dual-use-items

Gov.uk (3 de agosto de 2012). UK Strategic Export Control Lists. Recuperado de https://www.gov.uk/guidance/ uk-strategic-export-control-liststhe-consolidated-list-of-strategicmilitary-and-dual-use-items

Gov.uk (12 de septiembre de 2012). Standard Individual Export Licences.
Recuperado de https://www.gov. uk/guidance/standard-individualexport-licences

Gov.uk (14 de agosto de 2012). Open Individual Export Licences. Recuperado de https://www.gov.uk/ guidance/open-individual-exportlicences

Gov.uk (14 de abril de 2014). Annex E-Open Individual Export Licences: extant. Department for Business, Innovation \& Skills. Recuperado de https://www.gov.uk/government/uploads/system/uploads/ attachment_data/file/303323/supporting-doc-foi-140495-annex-e. CSv/preview

Gov.uk (diciembre de 2015). UK strategic export control list. Department for International Trade. Recuperado de https://www.gov.uk/government/uploads/system/uploads/ attachment_data/file/488993/controllist20151225.pdf

Gov.uk (26 de noviembre de 2015). PM call with President-elect Macri: 26 November 2015. Recuperado de https://www.gov.uk/government/news/pm-call-with-presidentelect-macri-25-november-2015

Gov.uk (21 de enero de 2016). PM meeting with President of Argentina: 21 January 2016. Recuperado de https://www.gov.uk/government/ news/pm-meeting-with-presidentof-argentina-21-january-2016

Gov.uk (12 de septiembre de 2016). Foreign Office Minister Sir Alan Duncan arrives in Argentina for bilateral talks. Recuperado de https:// 
www.gov.uk/government/news/ foreign-office-minister-sir-alanduncan-arrives-in-argentina-for-bilateral-talks

Gov.uk (14 de septiembre de 2016). UK and Argentina joint communiqué: 13 September 2016. Recuperado de https://www.gov. uk/government/publications/ communique-between-argentinaand-the-united-kingdom/uk-andargentina-joint-communique

Gov.uk (15 de septiembre de 2016). UK and Argentina agree joint statement on areas of mutual cooperation. Recuperado de https:// www.gov.uk/government/news/ uk-and-argentina-agree-joint-statement-on-areas-of-mutual-cooperation

Gov.uk (19 de diciembre de 2016). MOD: single departmental plan 2015 to 2020. Recuperadoel 9 de marzo de 2017, de https://www. gov.uk/government/publications/ mod-single-departmental-plan2015-to-2020

Gov.uk (2008b). Strategic Export Controls. Country Pivot Report. $1^{\text {st }}$ January $200831^{\text {st }}$ 2008. Recuperado de https://www.gov.uk/government/uploads/system/uploads/ attachment_data/file/559474/ strategic-export-controls-countrypivot-report-2008.pdf

Gov.uk (2009b). Strategic Export Controls. Country Pivot Report. $1^{\text {st }}$ January $200931^{\text {st }}$ 2009. Recuperado de https://www.gov.uk/government/ uploads/system/uploads/attach- ment_data/file/32928/sec-2009-ardata.pdf

Gov.uk (2010b). Strategic Export Controls. Country Pivot Report. $1^{\text {st }}$ January $201031^{\text {st }} 2010$. Recuperado de https://www.gov.uk/government/ uploads/system/uploads/attachment_data/file/32922/sec-countrypivot-report-09.pdf

Gov.uk (2011b). Strategic Export Controls. Country Pivot Report. $1^{\text {st }}$ January $201131^{\text {st }}$ 2011. Recuperado de https://www.gov.uk/government/uploads/system/uploads/ attachment_data/file/559651/ strategic-export-controls-countrypivot-report-2011.pdf

Gov.uk (2012b). Strategic Export Controls. Country Pivot Report. $1^{\text {st }}$ January $201231^{\text {st }}$ 2012. Recuperado de https://www.gov.uk/government/uploads/system/uploads/ attachment_data/file/559653/ strategic-export-controls-countrypivot-report-2012.pdf

Gov.uk (2013b). Strategic Export Controls. Country Pivot Report. $1^{\text {st }}$ January $201331^{\text {st }}$ 2013. Recuperado de https://www.gov. uk/government/uploads/system/uploads/attachment_data/ file/607849/2016Q4-strategicexport-controls-country-pivot-report-2013.pdf

Gov.uk (2014b). Strategic Export Controls. Country Pivot Report. $1^{\text {st }}$ January $201431^{\text {st }}$ 2014. Recuperado de https://www.gov.uk/government/uploads/system/uploads/ attachment_data/file/583191/ 
strategic-export-controls-countrypivot-report-2014.pdf

Gov.uk (2015b). Strategic Export Controls. Country Pivot Report. $1^{\text {st }}$ January $201531^{\text {st }} 2015$. Recuperado de https://www.gov.uk/government/ uploads/system/uploads/attachment data/file/607865/2016Q4strategic-export-controls-countrypivot-report-2015.pdf

Gov.uk (2016). Strategic Export Controls. Country Pivot Report. $1^{\text {st }}$ January $201631^{\text {st }}$ 2016. Recuperado de https://www.gov. uk/government/uploads/system/uploads/attachment_data/ file/608027/2016Q4-strategicexport-controls-country-pivot-report-2016.pdf

Stockholm International Peace Research Institute [SIPRI] (1997). United Kingdom Strategic Export Controls: Annual Report 1997. Recuperado de https://www.sipri.org/ databases/national-reports/United\%20Kingdom

Stockholm International Peace Research Institute [SIPRI] (1998). United Kingdom Strategic Export Controls: Annual Report 1998. Recuperado de https://www.sipri.org/ databases/national-reports/United\%20Kingdom

Stockholm International Peace Research Institute [SIPRI] (1999). United Kingdom Strategic Export Controls: Annual Report 1999. Recuperado de https://www.sipri. org/databases/national-reports/United\%20Kingdom
Stockholm International Peace Research Institute [SIPRI] (2000). United Kingdom Strategic Export Controls: Annual Report 2000. Recuperado de https://www.sipri.org/ databases/national-reports/United\%20Kingdom

Stockholm International Peace Research Institute [SIPRI] (2001). United Kingdom Strategic Export Controls: Annual Report 2001. Recuperado de https://www.sipri.org/ databases/national-reports/United\%20Kingdom

Stockholm International Peace Research Institute [SIPRI] (2002). United Kingdom Strategic Export Controls: Annual Report 2002. Recuperado de https://www.sipri.org/ databases/national-reports/United\%20Kingdom

Stockholm International Peace Research Institute [SIPRI] (2003). United Kingdom Strategic Export Controls: Annual Report 2003. Recuperado de https://www.sipri.org/ databases/national-reports/United\%20Kingdom

Stockholm International Peace Research Institute [SIPRI] (2004). United Kingdom Strategic Export Controls: Annual Report 2004. Recuperado de https://www.sipri.org/ databases/national-reports/United\%20Kingdom

Stockholm International Peace Research Institute [SIPRI] (2005). United Kingdom Strategic Export Controls: Annual Report 2005. Recuperado de https://www.sipri.org/ 
databases/national-reports/United\%20Kingdom

Stockholm International Peace Research Institute [SIPRI] (2006). United Kingdom Strategic Export Controls: Annual Report 2006. Recuperado de https://www.sipri.org/ databases/national-reports/United\%20Kingdom

Stockholm International Peace Research Institute [SIPRI] (2007). United Kingdom Strategic Export Controls: Annual Report 2007. Recuperado de https://www.sipri.org/ databases/national-reports/United\%20Kingdom

Stockholm International Peace Research Institute [SIPRI] (2008). United Kingdom Strategic Export Controls: Annual Report 2008. Recuperado de https://www.sipri.org/ databases/national-reports/United\%20Kingdom

Stockholm International Peace Research Institute [SIPRI] (2009). United Kingdom Strategic Export Controls: Annual Report 2009. Recuperado de https://www.sipri.org/ databases/national-reports/United\%20Kingdom

Stockholm International Peace Research Institute [SIPRI] (2010). United Kingdom Strategic Export Controls: Annual Report 2010. Recuperado de https://www.sipri.org/ databases/national-reports/United\%20Kingdom

Stockholm International Peace Research Institute [SIPRI] (2011).
United Kingdom Strategic Export Controls: Annual Report 2011. Recuperado de https://www.sipri. org/databases/national-reports/United\%20Kingdom

Stockholm International Peace Research Institute [SIPRI] (2012). United Kingdom Strategic Export Controls: Annual Report 2012. Recuperado de https://www.sipri.org/ databases/national-reports/United\%20Kingdom

Stockholm International Peace Research Institute [SIPRI] (2013). United Kingdom Strategic Export Controls: Annual Report 2013. Recuperado de https://www.sipri.org/ databases/national-reports/United\%20Kingdom

Stockholm International Peace Research Institute [SIPRI] (2014a). United Kingdom Strategic Export Controls: Annual Report 2014. Recuperado de https://www.sipri.org/ databases/national-reports/United\%20Kingdom

Stockholm International Peace Research Institute [SIPRI] (2014b). Arms Industry Database. Recuperado de https://www.sipri.org/databases/armsindustry

Stockholm International Peace Research Institute [SIPRI] (2015). United Kingdom Strategic Export Controls: Annual Report 2015. Recuperado de https://www.sipri.org/ databases/national-reports/United\%20Kingdom 